\title{
LOS PLANES DE GESTIÓN Y LOS PROGRAMAS DE MEDIDAS EN LA DiRECTIVA MARCo DE AgUAS. Su CONFUSA TRANSPOSICIÓN AL DERECHO ESPAÑOL *
}

\author{
Antonio FANLO LORAS \\ CATEDRÁTICO DE DERECHO ADMINISTRATIVO \\ UNIVERSIDAD DE LA RIOJA
}

s $u$ m a $r$ i $o$

I. Los planes de gestión y los programas de medidas de la Directiva marco del agua. 2. El precedente catalán de los planes de gestión y los programas de medidas. 3. La confusa transposición al Derecho español de la DMA no debe desnaturalizar nuestro modelo de planificación hidrológica, sino fortalecerlo.

I. Los planes de gestión y los programas de medidas en la Directiva Marco del Agua.

La Directiva Marco del Agua establece como instrumentos para la consecución de los objetivos de calidad (buen estado del agua), los planes de gestión ${ }^{\mathrm{I}}$ de cuencas y los programas

\footnotetext{
* El presente trabajo se ha realizado en el marco del Proyecto de Investigación SEC2006-I5I30CO2-02, «Veinticinco años de Derecho Administrativo postconstitucional. Los cambios producidos (Parte complementaria)», financiado por la Dirección General de Investigación del Ministerio de Ciencia y Tecnología. Su contenido tiene su origen en la exposición más extensa presentada en la Ponencia General sobre «La Planificación hidrológica», en el II Congreso Nacional de Derecho de Aguas, celebrado en Murcia los días 22 a 25 de noviembre de 2005.

I Las primeras versiones al castellano de la propuesta de Directiva Marco del Agua utilizan la denominación de «planes de gestión» de cuencas. Sin embargo, la versión final utiliza la expresión «planes hidrológicos» que es más apropiada con nuestra terminología legal. Esa equiparación terminológica tal vez ha contribuido a ocultar que no es posible equiparar el modelo de planes de la
} 
de medidas que deben elaborarse y aprobarse atendiendo a la diversidad de condiciones y necesidades de cada una de las demarcaciones hidrográficas que se delimiten por los Estados miembros. El objeto de las páginas que siguen es indagar qué son respectivamente tales instrumentos, cuál es su naturaleza y qué relación guardan entre sí, aspectos que no quedan suficientemente claros en la Directiva. Ello resulta imprescindible para articularlos adecuadamente en el Derecho español.

Para responder a estos interrogantes resulta imprescindible indagar en sus antecedentes. En este sentido, debo recordar que la Propuesta de DMA, de 26 de febrero de I997, [COM(97) 49 final, 97/0067 (SYN)], establece como objetivo general alcanzar un buen estado de las aguas a través de «una gestión en función de las cuencas fluviales; una evaluación de las características de cada cuenca fluvial; el control del estado de las aguas superficiales y subterráneas de la cuenca fluvial; el establecimiento de programas de medidas para alcanzar el objetivo; el resumen de todos los elementos anteriores en un 'plan de gestión de cuenca fluvial' y consultas públicas sobre este plan».

La Propuesta de DMA concebía los programa de medidas ${ }^{2}$ como «el elemento central de los planes de gestión de cuenca fluvial establecidos por la Propuesta marco». De acuerdo con esta concepción, el texto originario del art. I3) de la Propuesta de Directiva (actual art. II) decía: «Los Estados miembros garantizarán en cada distrito de cuenca fluvial el establecimiento de un programa de medidas encaminado a alcanzar los objetivos ambientales establecidos en el art. 4 . Los programas de medidas formarán parte de los planes de gestión de cuenca previstos en el artículo I6 (actual art. I3)». Esto es, los programas constituyen el elemento central de los planes, forman parte de los mismos, siendo su contenido de naturaleza normativa, administrativa o de acción, a la vista del contenido del entonces artículo iz de la Propuesta.

Cabe recordar que los programas de actuación son instrumentos tradicionales en las políticas de medio ambiente. Basta recordar los «programas de acción» de carácter general que fijan los objetivos prioritarios que hayan de alcanzarse que ha venido aprobando el Consejo de la Comunidad Europea en materia de medio ambiente (ahora estamos en el VII Programa de Medio Ambiente). El antecedente inmediato, no obstante, de los «programas de medidas» de la DMA está en el «programa» de la Directiva de sustancias peligrosas (76/464/CEE, de i8 de mayo de i976), que los Estados miembros debían elaborar para reducir la contaminación de las

DMA con nuestros planes hidrológicos. Tal vez no se ha reparado suficiente sobre esta cuestión, lo que ha podido suscitar interpretaciones erróneas. Los planes de la DMA parece que solo son meros instrumentos informativos. Pero ello no quiere decir que deban serlo también en el Derecho español. La ambigüedad o falta de perfil del modelo de la Directiva no tiene porqué trasladarse a nuestro ordenamiento jurídico. En virtud del principio de autonomía institucional el cumplimiento de la DMA no requiere, sin embargo, que deba alterarse la naturaleza jurídica de nuestros planes hidrológicos.

Otro tanto ocurre con la traducción de «cuenca» referida a los planes. «Cuenca» es la traducción que se corresponde con la expresión francesa de «district hydrologique». Pero adviértase que los planes de gestión deben extenderse a la «demarcación hidrográfica», que comprende la cuenca, las aguas de transición y las costeras, por lo que hubiera sido preferible que la versión definitiva de la DMA se refiriese a los «planes de gestión de las demarcaciones hidrográficas».

${ }^{2}$ Téngase en cuenta que en la Comunicación de la Comisión «Política de aguas de la Comunidad Europea» [COM (96) 59 final, de 2I de febrero de I996], ya aparecen mencionados como instrumentos claves los planes integrados de las cuencas fluviales, uno de cuyos elementos son los programas de medidas, FANLO LORAS, «La protección de las aguas», págs. 30-3I.

Redur 4/ 2006 
aguas producida por sustancias de la Lista II (la llamada lista «gris») ${ }^{3}$. Los programas de aquella Directiva son sustituidos en la DMA por los programas de medidas previstos en el art. I3 de la Propuesta (Apartado 3.I).

Sin embargo, la consideración de los programas de medidas como parte central de los planes de gestión se suprimirá en la posición común adoptada por el Consejo, en I9984. Esta supresión produce una relativa desvinculación entre ambos instrumentos lo que dificulta percatarse de la estrecha e indisociable relación que guardan entre sí.

De acuerdo con el art. II.2 DMA cada programa de medidas incluirá las «medidas básicas», previstas en el art. II.3 y, cuando sea necesario, las «medidas complementarias», concebidas y aplicadas con carácter adicional para lograr los objetivos ambientales establecidos en el art. 4 DMA. La parte B del Anexo VI contiene una lista no exhaustiva de posibles medidas complementarias. El contenido de estas medidas básicas y complementarias recogidas en las disposiciones citadas es diverso: van desde las medidas legislativas en sentido estricto o reglamentarias adoptadas a nivel nacional para la totalidad del territorio de un Estado miembro, para una demarcación o parte de ella hasta simples actos administrativos, ejecución de infraestructuras, actuaciones, etc.

Así, por ejemplo, las medidas necesarias para cumplir la normativa europea sobre protección de las aguas [art. I3.3.a) DMA], requiere, en principio, de medidas legislativas y reglamentarias generales o cuya concreción se confiar a los planes hidrológicos. Son necesarias, además, medidas administrativas concretas (autorizaciones, registros, actuaciones de control, de seguimiento, etc.). Esas medidas ya estaban previstas y eran exigibles en la legislación de algunos Estados miembros. Y eso mismo ocurre con las demás medidas previstas en el art. I3.3 DMA, la mayoría de las cuales ya estaban recogidas en el Derecho de Aguas español, con anterioridad a la propia DMA. Es el caso de la planificación hidrológica, del Registro de Aguas, del sistema de concesiones demaniales o las autorizaciones de vertidos, de contenido objetivo más extenso en nuestro Derecho que el derivado de la Directiva de sustancias peligrosas 5 .

No cabe prejuzgar el contenido y naturaleza de las medidas concretas que cada Estado miembro debe adoptar, pues dependerá del grado de institucionalización de su Derecho de Aguas, de su situación de partida previa. Al tratarse de una Directiva, los Estados están obligados a alcanzar el resultado establecido (buen estado de las aguas), pero -pese al detallismo excesivo de la DMA en determinados aspectos- no están predeterminados las medidas o instrumentos concretos que deba aplicar cada Estado miembro, de acuerdo con el principio de autonomía institucional. Caben pues, muy diferentes actuaciones, en función, como queda señalado, de la realidad legislativa y administrativa previa existente en cada Estado.

\footnotetext{
${ }^{3}$ Sobre el significado de la Directiva de sustancias peligrosas, véase E. Alonso GARCíA, El Derecho ambiental de la Comunidad Europea, vol. I El marco constitucional de la política comunitaria de medio ambiente. Aplicación de la legislación ambiental comunitaria, Civitas, Madrid, I993 y FANLo LoRAS, «La protección de las aguas», Noticias de la Unión Europea, num. I53(I997), págs. 24-26.

${ }^{4}$ No he encontrado (o no he podido encontrarla), en el complejo y, en ocasiones, opaco proceso de elaboración de las Directivas, la justificación de esa supresión.

${ }^{5}$ Sobre ello FANLO LORAS, «La protección de las aguas», pags. 3I-34 y FANLO LORAS, «La protección de la calidad de las aguas...», págs-3526-3529.
} 
En este sentido, resulta especialmente significativa la sorprendente simplicidad de la transposición francesa de las normas relativas a los programas de medidas de la DMA. Según la Ley 2004-338, de 2I de abril de 2004, de transposición de la citada Directiva, «los programas de medidas y las decisiones administrativas en el ámbito del agua deben ser compatibles con las disposiciones de los Planes Directores de Ordenación y Gestión de las Aguas (SDAGE)», art. 2I2-I.XI del Code de l'environnement. Y añade, «la autoridad administrativa establece y revisa periódicamente para cada cuenca o grupo de cuencas un programa plurianual de medidas que contribuyan a la realización de los objetivos y las disposiciones del SDAGE. Este programa así como su revisión periódica serán informados por el Comité de Cuenca» (art. 212-2-1, Code de l'environnement). Ya no hay más referencias al programa de medidas en la ley de transposición.

En el caso del España, la mayor parte de los contenidos de los programas de medidas están incorporados a normas legislativas o reglamentarias generales (TRLAg y normas reglamentarias) o forman parte de las determinaciones de contenido normativo de los planes [caso de las previstas en el art. I3.3 letras a), c), d), e), f), g), h), i), j), k) y l) DMA] y no era necesario transponerlas a nuestro Derecho, adviértase esta afirmación de extraordinaria importancia; otras, son parcialmente nuevas, como la relativa a la aplicación del principio de recuperación de costes [art. 13.3. letra b) DMA], dado que ya existe, en nuestro Derecho, un régimen económico-financiero aplicable al dominio público hidráulico, aunque con ciertas insuficiencias, especialmente en el terreno de su aplicación efectiva ${ }^{6}$.

De lo expuesto con anterioridad, puede concluirse que la DMA reserva a los programas de medidas aquellas actuaciones de contenido regulador ${ }^{7}$, normativas o de implementación secuenciada imprescindibles para asegurar la consecución de los objetivos ambientales fijados por los planes de gestión de cada una de las demarcaciones hidrográficas delimitadas por los Estados miembros.

Pero junto a la dimensión «ordenadora» o «normativa» de los programadas de medidas, ha de resaltarse la idea de «programación estratégica» o de «implementación secuenciada», esto es, la previsión precisa de plazos y modos de conseguir los objetivos a cumplir previamente predeterminados, aspecto en el que es muy deficitario nuestro modelo de planificación hidrológica, pese a la existencia de dos horizontes temporales. Es indudable que este componente dotará a nuestro modelo de planificación del elemento técnico-operativo (coercitivo o constrictivo, si se quiere) imprescindible para garantizar los resultados perseguidos en los plazos preestablecidos.

En cuanto a los planes de gestión, la regulación de la DMA es muy escueta, limitada a exigir que deben elaborarse planes de gestión para cada una de las demarcaciones hidrográficas que se delimiten (art. I3.I DMA), con las particularidades de las internacionales compartidas por Estados miembros o con países extracomunitarios. El contenido de los planes incluirá la información prevista en el Anexo VII de la DMA. Cabe la posibilidad de aprobar programas y

6 En relación con el régimen económico financiero resulta imprescindible EMBID IRUJO, «Condicionamientos jurídicos de una política de precios del agua», en EMBID (Director), Precios y mercados del agua, Civitas, Madrid, I996, págs. 23-II6 y la bibliografía allí citada. Véase un resumen de esta problemática en FANLO LORAS, La gestión del agua..., pág. 49-54.

${ }^{7}$ DeLgado PiQueras, «La planificación hidrológica en la Directiva marco comunitaria del agua» en E. PÉrez PÉreZ, Aplicación en España..., pág. 87.

Redur 4 / 2006 
planes de gestión mas detallados relativos a subcuencas, sectores, cuestiones específicas o categorías de aguas. Y, finalmente, la DMA establece la fecha en que los planes «se publicarán» (22 de diciembre de 2009), así como las de su revisión y actualización (22 diciembre de 20I5) y, las siguientes, cada seis años.

Si se analiza el contenido obligatorio de los planes de gestión del Anexo VII DMA, recogido en el cuadro comparativo incluido al final de este trabajo, puede constatarse que prácticamente todos ellos (salvo el del apartado A.5) se refieren a contenidos de naturaleza -en la terminología que ya nos es conocida- cognoscitiva o meramente informativa, pues respecto del contenido de los programas de medidas, que acaban de ser analizados, tan sólo se exige la inclusión de un «resumen» (informativo, en consecuencia) que incluya, de acuerdo con el art. II.3, los modos de conseguir los objetivos ambientales.

En dicho Anexo VII, el único contenido al que pudiera atribuirse naturaleza normativa es, como queda señalado, el del apartado A.5 (lista de los objetivos ambientales) y ello, siempre que la palabra «lista» no se entienda en sentido literal, pues en ese caso, también cabría calificar su naturaleza de meramente informativa. La «lista» puede que incluya, por el contrario, la relación de objetivos ambientales para las aguas superficiales, subterráneas y las zonas protegidas, previamente caracterizadas según las condiciones de referencia que les correspondan, así como las prórrogas, objetivos menos rigurosos y excepciones que el plan de gestión debe establecer y justificar, de acuerdo con el art. 4, apartados 4, 5, 6 y 7 DMA.

Es comprensible, a la vista de los expuesto, que se haya calificado el modelo de planificación de la Directiva Marco como de contenido meramente informativo (DELGADO PIQUERAS y CARO-PATÓN) ${ }^{8}$, por el predominio del contenido cognoscitivo o informativo de los planes de gestión y la atribución de los contenidos «normativos» a los programas de medidas. Sin embargo, esta valoración debe matizarse para evitar conclusiones precipitadas, cuando se proyectan sobre el modelo español de planificación hidrológica. De una parte, los planes de gestión tienen reservadas en la Directiva Marco funciones de naturaleza «reguladora»o «normativa», como establecer los objetivos ambientales para las distintas masas de agua, caracterizadas según las condiciones de referencia que procedan; o fijar las prórrogas y excepciones para el cumplimiento de los objetivos ambientales (art. 4, apartados 4, 5, 6 y 7 DMA) o, finalmente, fijar los motivos para no aplicar el principio de recuperación de costes (art. 9.4 DMA).

Es preciso resaltar que los planes de gestión y los programa de medidas no son instrumentos contrapuestos, sino estrechamente interdependientes, pues, como ha quedado apuntado, los programas de medidas «formaban parte» de los planes de gestión, en la Propuesta inicial de DMA, constituían su «elemento centrab. Y es que la técnica planificatoria incluye, como elementos estructurales necesarios e indisociables que forman una unidad, los elementos informativos-cognoscitivos, normativos y técnico-operativos, como he señalado con anterioridad.

\footnotetext{
${ }^{8}$ Han resaltado el contenido predominantemente informativo de los «nuevos» planes DELGAdo PIQUERAS, «La transposición...», pág. 204 y CARO-PATÓN CARMONA, «La Directiva marco de aguas y su transposición al Derecho español: análisis jurídico general», de próxima publicación en Revista Aranzadi de Derecho Ambiental, que conozco gracias a la amabilidad de su autora. Esta autora señala expresamente que «nuestros planes de cuenca han transformado su naturaleza perdiendo en gran medida su labor reguladora (que pasa a los programas de medidas) para convertirse en un conjunto de análisis y documentos informativos».
} 
Por todo ello, cabe relativizar la naturaleza meramente informativa de los planes de gestión por el contenido necesariamente ambiguo que, con frecuencia, tienen las Directivas (explicable por la pretensión de dar cobertura a la diversidad de modelos de los distintos Estados miembros), cuando no es contradictorio o falto de rigor, en estrictos términos jurídicos. En este sentido, es oportuno recordar que, ante las previsibles dificultades de aplicación de la Directiva Marco (de extraordinaria complejidad, como el tiempo ha confirmado), los Estados acordaron una estrategia común para su implementación [Common Implementation Strategy for the Water Framework Directive (2000/60/EC)]. Sin embargo, las Guías aprobadas, al margen de que carecen de fuerza vinculante, son muy vagas y genéricas. No es una excepción, la Guía II, relativa al proceso de planificación, en la que apenas se dedican un par de páginas a la tipología de planes y en las que no se encontrará respuesta a los problemas aquí examinados, por el enfoque predominantemente funcionalista e interactivo del proceso de planificación, alejado de las categorías jurídicas ${ }^{9}$.

En definitiva, no cabe sacralizar el modelo de plan de gestión de la DMA de naturaleza meramente informativa, pues no cabe entenderlo desligado de las determinaciones de contenido normativo y técnico-operativos, propias de los programas de medidas. Un plan meramente «informativo» carece de virtualidad aplicativa. La tradicional ambigüedad, imprecisión y falta de rigor jurídico de las Directivas no puede servir -antes al contrario- para proyectarla al Derecho español con el efecto de alterar, al amparo de una hipotética exigencia de la DMA, nuestro modelo de planes hidrológicos. Su naturaleza normativa (para ser más precisos, su naturaleza compleja: cognoscitiva, normativa y técnico-operativa, como he señalado) es aceptada sin discusión y sus determinaciones obligatorias, exigibles también a los planes de las demarcaciones hidrográficas intracomunitarias, tiene naturaleza básica, según la STC 227/88.

Cuestión distinta es que, en el orden interno, el legislador estatal deba identificarse con rigor las determinaciones de contenido normativo, imprescindibles para garantizar las nuevas exigencias de la Directiva añadidas a las ya existentes, que deben formar parte esencial de los planes hidrológicos (y ser aprobados, en consecuencia, por el Gobierno de la nación) y aquellas otras ajenas al contenido obligatorio del Plan, de la competencia de otras Administraciones, aunque también necesarios para conseguir los objetivos ambientales. Pero sobre ello volveré en el siguiente apartado.

Para finalizar este apartado, es necesario mencionar el amplio proceso de participación del público en el proceso de elaboración e los planes de gestión al que se refiere el art. I4 DMA, suficientemente cubierto en España por mecanismos de participación orgánica

\footnotetext{
9 Se trata de la Guidance document $n^{o}$ II, Planning process, elaborada por el Grupo de trabajo 9, liderado por España. La Sección.2 esta dedicada a «General scope, functions and types of planning processes». Tampoco nos sirve, en relación con la configuración de planes y programas de medidas, el meritorio documento «Directiva 2000/60/CE. Análisis de transposición y procedimientos de desarrollo», elaborado por los servicios del Ministerio de Medio Ambiente, en abril de 2003, en el que se recogen las aportaciones de distintos grupos de trabajo constituidos para esa específica finalidad.
}

Redur 4 / 2006 
formalizada de los interesados, así como mecanismos de participación funcional (información pública y audiencia) ${ }^{\mathrm{IO}}$.

2. El precedente catalán de los planes de gestión y los programas de medidas.

Es oportuno resaltar que Cataluña fue pionera en la incorporación de las instituciones de la Directiva marco del agua a la Ley 6/1999, de i2 de julio, de ordenación, gestión y tributación del agua (en particular su Título IV, relativo a la planificación hidrológica, artículos 25 a 36), que se adelantó, no solo a la transposición del Estado, sino a la propia aprobación final de la Directiva Marco. Esta Ley ha sido derogada por el Decreto Legislativo 3/2003, de 4 de noviembre, por el que se aprueba el Texto Refundido de la legislación en materia de aguas de Cataluña, pero no se han modificado los preceptos relativos a la planificación, razón por la que citaré los preceptos vigentes, teniendo en cuenta que dicho contenido procede de la ley de I999.

$\mathrm{Su}$ art. 20, establece que integran la planificación hidrológica del Distrito de Cuenca Fluvial $^{\text {II }}$ de Cataluña, el plan de gestión, los programas de medidas y los programas de control. Por su parte, el art. 2I.I dispone que «el Plan de gestión debe prever, además de las determinaciones obligatorias que resulten de la legislación en materia de aguas, los requerimientos cualitativos, cuantitativos y económicos de la utilización del recurso, los instrumentos necesarios para proteger los sistemas hídricos y los criterios para calificar un proyecto o una obra hidráulica de interés prioritario para la Generalidad». Destaco que la ley catalana asume, como no podía ser de otra forma, las «determinaciones obligatorias» que la legislación estatal de aguas fije para los planes hidrológicos de sus cuencas internas.

Y en cuanto al programa de medidas, establece que «forma parte del Plan de gestión del Distrito de Cuenca Fluvial de Cataluña», (art. 22.I), configuración que, como se recordará, era la recogida en la Propuesta de Directiva Marco. Y añade el art. 22.2 que «el programa de medidas...concreta las prescripciones del Plan de Gestión del Distrito de cuenca y fija las actuaciones dirigidas a...» y sigue un extenso listado de objetivos ${ }^{\mathrm{I2}}$. Entre dichas actuaciones las

Io Sobre la participación en la Directiva Marco del Agua, P. IBÁNEZ, «La participation du public et l'eau en droit communautaire», Environnement, $n^{\circ}$ 7, juillet, 2005, págs. 9I-94; en la misma revista, P. IDOUX «Les eaux troubles de la participation du public», págs. 83-90 y FANLO LORAs, «Le modèle espagnol de participation du public à la gestion de l'eau: mythe, réalité et défis immédiats», págs. 77-82.

${ }^{\text {II }}$ El empleo de la expresión «Distrito de Cuenca Fluvial» se explica porque las versiones castellanas iniciales de la Propuesta de Directiva utilizaban este término, mientras que la versión final utiliza la expresión «demarcaciones hidrográficas».

${ }^{12}$ El art. 22.2 incluye, entre estas actuaciones, las dirigidas a:

a) La obtención de un inventario de los recursos hídricos en calidad y cantidad.

b) El abastecimiento de las poblaciones.

c) La determinación, la recuperación y la protección de los caudales ecológicos.

d) La recuperación, la protección y la mejora de la calidad de las aguas.

e) La recuperación, la conservación y la mejora de los ecosistemas vinculados al medio hídrico.

f) El establecimiento de un registro de zonas protegidas.

Redur 4 / 2006 
hay que corresponden sin ninguna duda a la Administración regional, tanto en las demarcaciones internas, como en las intercomunitarias (caso, por ejemplo, de los programas de «abastecimientos de las poblaciones»), si bien otras tienen que ver con el contenido obligatorio de los planes hidrológicos. Por ejemplo, las previstas en los párrafos c), d), g), m). No obstante, en relación con estas últimas pudiera tratarse, simplemente de las actuaciones operativas (de mera ejecución), para llevar a cabo las determinaciones de contenido normativo incluidas en los planes.

Si recojo esta mención de la legislación de Cataluña es porque, considero, que este precedente, ha podido condicionar la transposición estatal de la DMA y que algunas de las reglas recogidas en el TRLAg pueden obedecer, en el plano competencial, al respeto de las opciones previas adoptadas por la legislación catalana. Sin embargo, no puede ignorarse que el Tribunal Constitucional consideró básicos los contenidos de la planificación hidrológica, tal como estaban recogidos en el entonces art. 40 LAg. Es cierto que el art. 21.2 de la norma catalana, salva las «determinaciones obligatorias que resultan de la legislación en materia de aguas», pero al calificar determinados contenidos como propios de los programas de medidas, pueden quedar segregados de los planes, así como alterado el régimen competencial para aprobarlas.

3. La confusa transposición al Derecho Español de la DMA no debe desnaturalizar nuestro modelo de planificación hidrológica, sino fortalecerlo.

La Ley 62/2003, de 30 de diciembre, de medidas fiscales, administrativas y sociales, transpuso la Directiva Marco del Agua unos días más tarde del 22 de diciembre de 2003, fecha límite para ello ${ }^{\mathrm{I}}$. El temor a una sanción por incumplimiento del deber de transposición tal vez

g) El control de las captaciones y vertidos.

h) El ahorro, la optimización y la mejora de la eficiencia del uso del agua.

i) La prevención y la defensa contra las inundaciones.

j) El saneamiento y la depuración de las aguas residuales, incluyendo la descarga de sistemas unitarios.

k) La reutilización del agua procedente de estaciones depuradoras de aguas residuales.

1) La gestión de los lodos procedentes de sistemas públicos de potabilización y de saneamiento de aguas residuales.

m) La previsión de los colectores básicos de aguas pluviales.

n) El análisis económico del ciclo del agua en general y por sectores desglosándolo, al menos, en doméstico, industrial y agrícola.

o) La concreción del ámbito territorial de las ELA cualificadas.

p) El fomento de la difusión, la formación y la sensibilización en materia de ordenación y gestión del agua.

q) En general, la gestión de las masas de agua.

${ }^{13}$ Las primeras valoraciones de la transposición de la DMA las han hecho DELGADo PIQUERAS, «La transposición de la Directiva Marco de Aguas en España», RAP, I65, 2004, págs. I8I-2I3 y CARO-PATÓN CARMOnA, «La Directiva marco de aguas y su transposición al Derecho español: análisis jurídico

Redur 4 / 2006 
explique la utilización, a última hora, de ese inadecuado cauce normativo de la Ley de «acompañamiento».

En lo que afecta a los planes de gestión y a los programas de medidas, considero que no ha existido «transposición», en sentido técnico, de la Directiva Marco, sino simple «traslatio» o copia íntegra del contenido de su Anexo VII, que se ha añadido -reestructuradoal contenido del antiguo art. 40 LAg, resultando el extensísimo -y confuso- art. 42 TRLAg, que altera nuestro modelo de planificación hidrológica. El efecto acumulativo puede comprobarse en el «Cuadro evolutivo del contenido de los planes hidrológicos», incluido al final de este trabajo, gracias a los colores que identifican el cuerpo normativo del que proceden.

Considero que la transposición pudiera haberse hecho -como Francia- con unos ligeros retoques en el antiguo art. $40 \mathrm{LAg}$, llevando a las normas reglamentarias o a las instrucciones técnicas de coordinación, la prolija documentación, de naturaleza informativa, que deben recoger los planes, aspecto que no hay que confundir con sus determinaciones de contenido normativo. Y es que nuestro modelo de plan hidrológico no es contrario a la Directiva -antes al contrario-, aunque si requería ciertos añadidos para incluir lo no previsto: caracterización de las masas de aguas según las condiciones de referencia para garantizar su buen estado; análisis económico uso del agua para la aplicación del principio de recuperación de costes, sustitución de los objetivos de calidad según los usos, por el del buen estado y sus excepciones.

La transposición realizada denota una deficiente comprensión del modelo planificador de la Directiva Marco y de nuestro modelo, pues consagra la separación formal de planes y programas de medidas que desnaturaliza nuestro modelo de planificación hidrológica, en cuanto instrumento jurídico-administrativo de naturaleza normativa. El sistema resultante es confuso en el plano conceptual y se proyecta, con consecuencias disfuncionales, en el plano competencial, al vaciar parcialmente el contenido sustantivo de los planes sujeto a la aprobación del Gobierno, como luego se verá.

La transposición ha incurrido en injustificadas reduplicaciones, como pone de manifiesto la lectura de los artículos relativos a los programas de medidas [4I.2, 42.I.g), 92.bis.2 y 92.quater], que debieron haberse evitado. En otros casos, se ha incurrido en contradicciones. Así, en el 42.I.g) TRLAg, al referirse al resumen del programa de medidas que debe incluirse en el plan hidrológico, se copia el contenido de las medidas básicas, previstas en el art. II.3 DMA y, sin embargo, se afirma, en el art.92.quater.3.a), que las medidas básicas «se establecerán reglamentariamente».

Los planes hidrológicos y los programas de medidas quedan configurados como realidades distintas. Así, de acuerdo con el art. 4I.2 TRLAg, los programas de medidas se elaboran previamente a los Planes (aunque, en realidad, su elaboración corre simultánea con la de los planes); se coordinan e integran en el Plan, en especial, se coordinan los programas de medidas de aguas costeras y de transición, elaborados por la Administración General del Estado o por las Comunidades Autónomas que participen en el Consejo del Agua de la Demarcación y cuenten con litoral. Un resumen de los programas de medidas (a efectos meramente informativos), forma parte del contenido obligatorio de los planes [art. 42.I.g) TRLAg]. La

general», de próxima publicación en Revista Aranzadi de Derecho Ambiental, que conozco gracias a la amabilidad de su autora. 
finalidad de los programas de medidas es la consecución de los objetivos ambientales previstos (arts. 4I.2 y en igual sentido el 92.quater.2 TRLAg); los programas deben ser «especificados» en los planes hidrológicos y «concretar las actuaciones y las previsiones necesarias para alcanzar los objetivos medioambientales» (art. 92.bis.2 TRLAg). Quedarán integradas por las «medidas básicas y complementarias que, en el ámbito de sus competencias, aprueban por las Administraciones competentes en la protección de las aguas» (art. 92.quater.4 TRLAg), precepto que para nada se refiere al procedimiento de su elaboración ni si cabe la participación del público ${ }^{\mathrm{I}}$.

Ambos instrumentos tienen plazos de aplicabilidad distintos. Así, los programas de medidas deben ser «aprobados» antes del 3I de diciembre de 2009 (su actualización en el 2015 y su revisión cada seis años) y estar operativos en 2012 (Disposición Adicional II ${ }^{a} .2$ ). Los planes hidrológicos habrán de «revisarse» (pues, ya tenemos planes plenamente operativos, en España) para que entren en vigor antes del 3I de diciembre de 2009 (disposición Adicional $\mathrm{II}^{\mathrm{a}}$.6). Pero, en 2006 , debe haberse establecido un calendario y un programa de trabajo para su revisión; en 2007, debe fijarse el esquema provisional de los temas importantes; y en 2008, debe estar elaborado el proyecto de plan hidrológico (Disposición Adicional $12^{\mathrm{a}}$ ).

La separación entre planes hidrológicos y los programas de medidas, produce otras disfunciones, en el plano competencial, al atribuir su aprobación a diferentes Administraciones. En efecto, «el programa de medidas se integrará por las medidas básicas y las complementarias que, en el ámbito de sus competencias, aprueben las Administraciones competentes en la protección de las aguas», de acuerdo con el art.92.quater.4. Dicha disposición resulta equívoca, pues como he advertido, la mayor parte de los programas de medidas básicas (ex art. I3.3 DMA), forman parte de las determinaciones de contenido normativo de los planes hidrológicos y, en consecuencia, deben seguir su mismo régimen de aprobación (aprobación inicialmente por el Consejo del Agua de la Demarcación y final, por el Gobierno de la nación $)^{15}$.

${ }^{\text {I4 }}$ Delgado PiQUeRAS, «La transposición...», pág. 207.

I5 Una muestra reciente de las disfunciones competenciales que suscita esta transposición la encontramos en el reciente Real Decreto $1560 / 2005$, de 23 de diciembre (BOE 24 de diciembre de 2005), sobre traspaso de funciones y servicios del Estado a la Comunidad Autónoma de Andalucía en materia de recursos y aprovechamientos hidráulicos correspondientes a las cuencas andaluzas vertientes al litoral atlántico (Confederaciones Hidrográficas del Guadalquivir y del Guadiana). Este Decreto atribuye [en su apartado B.4.b)] la «elaboración y la determinación de actuaciones y de programa de medidas a incluir en los planes hidrológicos de demarcación relativas a las cuencas hidrográficas correspondientes a los ríos Guadalete y Barbate e intercuencas entre el límite de los términos municipales de Tarifa y Algeciras y el límite con la cuenca del Guadalquivir (cuencas internas de Andalucía antes adscritas a la Confederación Hidrográfica del Guadalquivir) y de los ríos Tinto, Odiel y Piedras y las cuencas correspondientes de vertido directo al Atlántico (cuencas internas de Andalucía antes adscritas a la Confederación Hidrográfica del Guadiana). Aun cuanto se trata de cuencas internas andaluzas, ya he señalado que algunos de los contenidos de los programas de medidas forman parte del contenido obligatorio de los planes, de naturaleza básica, cuya aprobación final corresponde al Gobierno de la Nación [así lo recoge el apartado C.c), para todos los planes hidrológicos de acuerdo con el art. 40 TRLAg], razón por la que la competencia de la Junta debiera considerarse, en ese caso, una mera 'propuesta'. Asimismo, atribuye «la propuesta de actuaciones y de programas de medidas a incluir en los planes hidrológicos de demarcación» de las cuencas hidrográficas andaluzas vertientes al tramo internacional del río Guadiana, dentro de la provincia de Huelva, desde la confluencia del río Chanza, incluida la cuenca de éste, hasta su desembocadura en el Atlántico. Esta última subcuenca, pertenece en sentido estricto a la cuenca del 
Por Administración competente deben entenderse, en el caso de las demarcaciones hidrográficas intercomunitarias, las Confederaciones Hidrográficas y en las intracomunitarias, las Comunidades Autónomas. En ambos casos, la aprobación final de los planes, siempre al Gobierno de la Nación.

Ahora bien, a la vista del contenido de planes y programas, el meollo de la cuestión (evidenciado por el art. 22 del Texto Refundido de la legislación en materia de aguas de Cataluña), es determinar qué contenidos forman parte necesaria del plan hidrológico y cuáles son los programas de medidas, ajenos al mismo, esto es que no tienen la consideración de determinaciones de contenido normativo del plan y son susceptibles de ser elaborados, aprobados y ejecutados por otras Administraciones. Ese deslinde es el que resulta confuso tras la transposición realizada.

En efecto, la observación atenta del Cuadro evolutivo referido incluido al final de este trabajo, permite constatar visualmente como parte del contenido obligatorio de los planes [art. 40, letras e), g), i), f), k), l) y j) LAg], ha pasado a integrar los programas de medidas [art. 42.I.g), letras d'), i'), k'), l'), m', n') y o')]. Para CARO-PATÓN ${ }^{16}$, «el contenido obligatorio de los planes de nuestra legislación anterior a la transposición se ha separado en dos partes. Por un lado, todos los aspectos relativos a los estudios, inventarios, análisis, etc., que siguen formando parte de la nueva planificación; y por otro lado, la práctica totalidad del anterior contenido ordenador que ha pasado a los programas de medidas. Podemos afirmar que nuestra planificación se ha plegado a la prevista por la DMA, que es fundamentalmente información si bien corresponde a los planes adoptar algunas decisiones». Para la autora, los planes son documentos fundamentalmente informativos, al perder la función reguladora que ha pasado a los programas de medidas, cambio que inicia para ella la necesaria flexibilización de nuestro sistema de planificación.

Sin embargo, no comparto esta valoración que supone aceptar la separación formal entre planes hidrológicos y programa de medidas que quiebra e ignora la íntima conexión que existe entre ambas realidades, pues el plan hidrológico, en nuestra legislación de aguas, es un documento complejo de elementos cognoscitivos, normativos y técnico-operativos, sin los cuales el plan carece de virtualidad ordenadora de la realidad. El plan es un conjunto unitario integrado por documentos de naturaleza distinta, pero interrelacionada, que adquieren su sentido por relación a los demás, a condición -claro está- de que implemente adecuadamente las remisiones normativas confiadas.

Pero con independencia de la supuesta «desnaturalización», los planes hidrológicos siguen conservando importantes contenidos normativos relativos a los usos y demandas existentes; criterios de prioridad y compatibilidad de usos y orden de preferencia; asignación y reserva de usos; caudales ecológicos; reservas naturales fluviales; al sistema de explotación único [art. 42.I.b), a', b', c', d' TRLAg]. Como tienen contenido normativo la mayor parte de los

Guadiana, sin perjuicio de que concurra la circunstancia de que esté ubicada -la subcuencaíntegramente en Andalucía, razón por la que el Estado se reserva la concesión de recursos hidráulicos, las autorizaciones de vertidos a cauces públicos y las relativas al uso o aprovechamiento del dominio público hidráulico, la resolución de los actos relativos a la policía de aguas y cauces así como la aplicación del régimen sancionador en materia de aguas. Esta pertenencia a la cuenca del Guadiana explica que en este caso, solo se hable de «propuesta» de programa de medidas.

${ }^{16}$ CARO-PATÓn CARMONA, «La Diectiva Marco...». 
supuestos que ahora han pasado a formar parte ahora del programa de medidas ${ }^{17}$, extremo que fue determinante para reconocer su naturaleza básica por la STC 227/88. En definitiva, entiendo que la Directiva Marco no impone ni justifica una desnaturalización de nuestro modelo de planificación hidrológica, de naturaleza normativa, en los términos ya señalados, razón por la que debiera rectificarse el sistema confuso establecido.

La disfunción en el plano competencial es especialmente patente -en mi opinión- en el caso de los programas de medidas relativos a las aguas costeras y transición, cuestión que tiene, además, su proyección organizativa relacionada con la configuración de la demarcación hidrográfica ${ }^{\mathrm{I} 8}$. En efecto, estos programas serán «elaborados por la Administración General del Estado o por las Comunidades Autónomas que participen en el Comité de Autoridades Competentes de la demarcación y que cuenten con litoral» (art. 4I.2, párrafo tercero TRLAg). La inadecuada separación de los programas de medidas y los planes está en la base y se proyecta sobre esta atribución competencial que considero equivocada, pues quiebra el principio de unidad de gestión en la fijación de los objetivos de calidad para toda la demarcación.

La fijación de los objetivos de calidad de las aguas costeras y las aguas de transición debe hacerse, en el marco del plan de la demarcación (si se quiere, dentro de ese específico programa), por el Consejo del Agua de la Demarcación, en el que están representadas todas las Administraciones con competencia en esas aguas. No cabe una elaboración «externa», de la Administración competente (sea de la Administración General del Estado o de la Comunidad Autónoma costera) y fijados por ésta los objetivos de calidad, éstos se «coordinan» para su integración en el Plan. No es posible, sin romper el principio de unidad de planificación de la cuenca o demarcación $^{\text {I9 }}$, admitir la posibilidad de que para partes concretas de la misma (aguas costeras, aguas de transición) los objetivos de calidad los fije una Administración distinta del órgano de planificación de la demarcación. Entiendo, por ello, que el Consejo del Agua de la Demarcación es, por su composición y funciones, un órgano de coordinación. Y, en consecuencia, en su seno deben fijarse los objetivos de calidad, sin perjuicio de que la ejecución de los programas pertinentes, corresponda a las Comunidades Autónomas litorales (para las aguas costeras y las de transición ${ }^{20}$ ) y a la Confederación Hidrográfica (para las aguas de la cuenca).

${ }^{17}$ Cabe admitir que «las infraestructuras básicas» [art. 42.I.g).o') TRLAg] pasen a integrar un programa de medidas específico, dada su naturaleza técnico-operativa, así como que en los demás supuestos puedan identificarse, junto a los elementos normativos, otros técnico-operativos. Pero ello no debiera llevar, por las razones expuestas a segregarlos, con las consecuencias apuntadas en el plano competencial.

${ }^{18}$ Sobre esta cuestión FANLO LORAS, «La adaptación de la Administración Pública Española a la Directiva Marco Comunitaria del Agua», en PÉREZ PÉREZ (Coordinador) Aplicación en España..., págs. I53-I78. También, con planteamientos parcialmente diferentes, CARO-PATÓN CARMONA, «La Directiva Marcote Aguas...».

${ }^{19}$ CARO-PATÓn CARMONA sostiene que «para las demarcaciones, como nuevo ámbito espacial, ya no rige el principio de unidad de gestión o de gestor único», «La Directiva marco...». Comparto esta valoración en su sentido literal (la gestión), pero no, en cuanto a la planificación, pues los objetivos de calidad deben adoptarse de manera conjunta para toda la demarcación, en el seno del Consejo del Agua de la Demarcación.

${ }^{20}$ Conviene recordar la DMA y la Ley de Costas utilizan criterios distintos para delimitar las aguas de transición, y la extensión de la zona del dominio marítimo-terrestre. La DMA utiliza el criterio de la «salinidad» del agua (parcialmente salinas por su proximidad a las aguas costeras, pero con notable

Redur 4 / 2006 
En conclusión, no puede confundirse el contenido obligatorio de los planes con las determinaciones de contenido normativo inherentes al plan hidrológico. El Plan forma un todo, una unidad global de sentido con elementos cognoscitivos, normativos y técnico-operativos, esto es, medidas para alcanzar los objetivos perseguidos. Lo normativo solo se predica de ciertos elementos del plan. Pero esos elementos deben existir para que el plan cumpla su función ordenadora querida y encomendada por la Ley. Constituyen su parte «normativa». Pero esta requiere del complemento de un programa de medidas adecuadas a los objetivos a alcanzar. Por eso, los planes hidrológicos de las demarcaciones hidrográficas no son meros documentos «informativos», como algunos han sostenido. No han perdido la sustancia normativa, depositada ahora en los programas de medidas. Los planes seguirán siendo un ejemplo prototípico de «remisión normativa» de la Ley al plan, que, rectificada la confusa transposición realizada, saldrán fortalecidos.

influencia de flujos de agua dulce, art. 2.6 DMA), mientras que la Ley de Costas emplea para deslindar el dominio público marítimo-terrestre en los márgenes de los ríos, el criterio de la «sensibilidad a las 'mareas'» [art. 3.I.a) LCo]. Adviértase que dichas normas persiguen finalidades diferentes, razón por la que sus criterios no son plenamente coincidentes. 